\title{
Mortality After the Hospitalization of a Spouse
}

\section{Citation}

Christakis, Nicholas A. and Paul D. Allison. 2006. Mortality after the hospitalization of a spouse. New England Journal of Medicine 354, no. 7: 719-730.

\section{Published Version}

http://dx.doi.org/10.1056/NEJMsa050196

\section{Permanent link}

http://nrs.harvard.edu/urn-3:HUL.InstRepos:3685835

\section{Terms of Use}

This article was downloaded from Harvard University's DASH repository, and is made available under the terms and conditions applicable to Other Posted Material, as set forth at http:// nrs.harvard.edu/urn-3:HUL.InstRepos:dash.current.terms-of-use\#LAA

\section{Share Your Story}

The Harvard community has made this article openly available.

Please share how this access benefits you. Submit a story.

\section{Accessibility}


SPECIAL ARTICLE

\section{Mortality after the Hospitalization of a Spouse}

Nicholas A. Christakis, M.D., Ph.D., M.P.H., and Paul D. Allison, Ph.D.

\section{A B STRACT}

\section{BACKGROUND}

The illness of a spouse can affect the health of a caregiving partner. We examined the association between the hospitalization of a spouse and a partner's risk of death among elderly people.

\section{METHODS}

We studied 518,240 couples who were enrolled in Medicare in 1993. We used Cox regression analysis and fixed-effects (case-time-control) methods to assess hospitalizations and deaths during nine years of follow-up.

\section{RESULTS}

Overall, 383,480 husbands (74 percent) and 347,269 wives (67 percent) were hospitalized at least once, and 252,557 husbands (49 percent) and 156,004 wives (30 percent) died. Mortality after the hospitalization of a spouse varied according to the spouse's diagnosis. Among men, 6.4 percent died within a year after a spouse's hospitalization for colon cancer, 6.9 percent after a spouse's hospitalization for stroke, 7.5 percent after a spouse's hospitalization for psychiatric disease, and 8.6 percent after a spouse's hospitalization for dementia. Among women, 3.0 percent died within a year after a spouse's hospitalization for colon cancer, 3.7 percent after a spouse's hospitalization for stroke, 5.7 percent after a spouse's hospitalization for psychiatric disease, and 5.0 percent after a spouse's hospitalization for dementia. After adjustment for measured covariates, the risk of death for men was not significantly higher after a spouse's hospitalization for colon cancer (hazard ratio, 1.02; 95 percent confidence interval, 0.95 to 1.09) but was higher after hospitalization for stroke (hazard ratio, 1.06; 95 percent confidence interval, 1.03 to 1.09), congestive heart failure (hazard ratio, 1.12; 95 percent confidence interval, 1.07 to 1.16), hip fracture (hazard ratio, 1.15; 95 percent confidence interval, 1.11 to 1.18), psychiatric disease (hazard ratio, 1.19; 95 percent confidence interval, 1.12 to 1.26), or dementia (hazard ratio, 1.22; 95 percent confidence interval, 1.12 to 1.32). For women, the various risks of death after a spouse's hospitalization were similar. Overall, for men, the risk of death associated with a spouse's hospitalization was 22 percent of that associated with a spouse's death (95 percent confidence interval, 17 to 27 percent); for women, the risk was 16 percent of that associated with death (95 percent confidence interval, 8 to 24 percent).

\section{CONCLUSIONS}

Among elderly people hospitalization of a spouse is associated with an increased risk of death, and the effect of the illness of a spouse varies among diagnoses. Such interpersonal health effects have clinical and policy implications for the care of patients and their families.
From the Department of Health Care Policy, Harvard Medical School, and the Palliative Care Service, Department of Medicine, Massachusetts General Hospital — both in Boston (N.A.C.); the Department of Sociology, Harvard University, Cambridge, Mass. (N.A.C.); and the Department of Sociology, University of Pennsylvania, Philadelphia (P.D.A.). Address reprint requests to Dr. Christakis at the Department of Health Care Policy, Harvard Medical School, 180 Longwood Ave., Boston, MA 02115, or at christakis@hcp.med. harvard.edu.

N Engl J Med 2006;354:719-30. Copyright (c) 2006 Massachusetts Medical Society. 
T HE HEALTH OF PEOPLE CONNECTED BY A social tie may be interdependent. The effect of the death of one spouse on the risk of death in the other (i.e., the partner) - referred to as the bereavement effect - is the best-documented example of such interpersonal health effects. ${ }^{1,2}$ The effect of illness in one spouse on the risk of illness in a partner is a further example. The latter phenomenon, sometimes termed caregiver burden, ${ }^{3,4}$ has typically been studied as if it were unrelated to the bereavement effect. Indeed, most work has previously focused on how spousal illness worsens the health of partners and not on whether it increases their mortality. ${ }^{5}$

However, studying the bereavement effect and caregiver burden in concert may advance the understanding of both. Examining the two phenomena together provides an opportunity to assess the implications of spousal diseases with potentially variable lethality. Moreover, spousal illnesses can vary in ways beyond their lethality. Studies have shown that a decrease in physical health in a spouse is linked to a decrease in health in a partner ${ }^{4,6}$ and that mental impairment may be even more burdensome than physical impairment. ${ }^{4,7-9}$ Very few studies, however, have compared diseases in terms of their health implications for partners or exploited this variation to better understand interpersonal health effects more generally.

We used a large national sample with a long period of follow-up and reliable ascertainment of health events to investigate such effects. We hypothesized that the hospitalization of a spouse with a serious illness would be associated with an increase in the risk of death of a partner, that this association would be distinct from the effect of having a spouse die, that this association would vary among spousal illnesses of varying degrees of burden, and that this phenomenon would vary according to the time that had elapsed since the hospitalization.

\section{METHODS}

\section{STUDY POPULATION}

To assemble a very large cohort with sufficient temporal and diagnostic detail, we compiled raw Medicare claims. Medicare beneficiaries who were 65 years of age or older on January 1, 1993, were identified in the Denominator File. This file contains all beneficiaries, whether they use health care or not, and captures data on 96 percent of elderly Americans. ${ }^{10}$ Among the 32,180,588 elderly people in this file, Census statistics suggested that there were 6.6 million married couples of which both members were older than 65; from this group, we identified 5,496,444 couples ( 83 percent). ${ }^{11,12}$ Of these, $4,874,817$ couples were between the ages of 65 and 98 years and resided in the United States. From this group, we chose a random sample of 540,793 couples (11.1 percent) who were identified with one detection method. After excluding 22,553 couples in which the partners resided in different ZIP Codes, 518,240 couples were left.

Using the Vital Status File, we obtained daily mortality follow-up through January 1, 2002. Using Medicare Provider Analysis and Review records for 1993 to 2002, we obtained admission dates and reasons for all hospitalizations. The principal diagnosis (according to diagnosis codes of the International Classification of Diseases, Ninth Revision, Clinical Modification) was categorized with the use of a 49-category indicator on the basis of a taxonomic system used by the Centers for Disease Control and Prevention. ${ }^{13}$ For parsimony, the diagnoses were collapsed into 16 categories. Other analyses with use of all 49 categories yielded similar results (data not shown).

With hospital claims, it is possible to ascertain cases of serious diseases (e.g., stroke, lung cancer, and abdominal surgery) very reliably. ${ }^{14-16}$ In some cases, the disease could have been noted before hospitalization (e.g., during outpatient visits), but our interest here was in the type of serious disease necessitating hospitalization. Each person in each couple could have multiple hospitalizations during follow-up (though 60 percent had no more than two hospitalizations), but we recorded only the first hospital admission for each spouse after January 1, 1993, and we ignored any subsequent admissions. We used hospitalization as a marker for the occurrence of a serious spousal illness that was either generally permanent (e.g., lung cancer or congestive heart failure) or, in fewer cases, circumscribed (e.g., abdominal surgery).

For each person, we examined three years of inpatient claims before January 1, 1993, in order to establish a baseline illness burden. For this reason, patients had to be at least 68 years of age for certain analyses (i.e., the Cox models) because younger persons could not have claims available for the entire period from 1990 to 1992 . We used 
the Charlson score to summarize baseline morbidity, divided into categories of 0,1 , or 2 or more, with higher scores indicating a greater burden of morbidity. ${ }^{14}$ We also counted the number of weeks that each person had spent in the hospital from 1990 to 1992. For certain analyses, we excluded couples in which either person was enrolled in a staff-model health maintenance organization $(<7$ percent), since it is not possible to obtain all the health care claims of such persons. The measures of age, race, ${ }^{17}$ and poverty ${ }^{18}$ that we used have been validated. The study was approved by our institutional review boards.

\section{STATISTICAL ANALYSIS}

We used two complementary methods: Cox regression analysis and a fixed-effects (case-timecontrol) method. The former analysis offered the advantage of providing an explicit estimation of the effects of measured attributes on the outcome of interest and, more important, permitted a flexible model specification that allowed for separate estimation and comparison of the effects of spousal hospitalization and spousal death. The latter method offered the substantial advantage of controlling for unmeasured factors that might confound the effects of interest.

In the Cox models, the dependent variable was the duration of survival of the partner of a potentially sick spouse from January 1, 1993, until January 1, 2002. We treated the hospitalization of a spouse and the death of a spouse as separate time-varying covariates, with the result that the estimate of the effect of the hospitalization of a spouse was independent of whether the spouse died. In the models reported here, we designated the time-varying indicator of spousal hospitalization as 0 until the spouse was hospitalized (if at all), then raised the indicator to 1 on hospitalization; this indicator reverted to 0 with the death of the spouse. When diagnosis-specific hospitalization was used, there were 16 analogous, mutually exclusive indicators. We designated the time-varying indicator of spousal death as 0 until the spouse died and as 1 thereafter. In this model, the effect of a spouse's death on the partner's risk of death did not depend on whether a spouse who died had previously been hospitalized. We also specified additional models (not shown) in which there was one indicator for a spousal death with no previous hospitalization and another indicator for spousal death with pre- vious hospitalization, in addition to the indicator of spousal hospitalization itself. The point estimate of the difference between the hazard ratio associated with the death of a spouse who was previously well and the hazard ratio associated with the death of a spouse who was previously sick was very small and not statistically distinguishable from zero. Therefore, we present simpler models here that are not as elaborately specified when it comes to the types of spousal death. Regardless, these models do not differ with respect to the types of spousal illness.

Our alternative analytic approach, the casetime-control method, allowed us to estimate the relationship between the hospitalization of a spouse and the subsequent death of the partner while controlling for all constant characteristics of the spouses and their environment. These characteristics could include poverty history, smoking history, educational level, and toxic exposures, whether such characteristics were measured or unmeasured. ${ }^{19-21}$ Our implementation involved a parsing of the exposure period into couple-days and an estimation of a conditional logistic regression in order to model the risk of death of a partner on a particular day as a function of spousal hospitalization within a specified previous time period.

Briefly, for each couple, we created one record for each day the couple was observed, up to and including the day the partner died or data on the couple were censored. The variable of death of a partner was designated as 1 if the partner died on that particular day; otherwise, the designation was 0 . The variable of hospitalization of a spouse was designated as 1 if the spouse was hospitalized within 30 days (or other time periods, as outlined below) before that particular couple-day; otherwise, the designation was 0 . Thus, this variable was designated as 0 for the initial couple-days, was switched to 1 when the spouse was hospitalized, stayed at 1 for a period of 30 days (or some other period of time), and then switched back to 0 .

Once this working data set was created, we estimated a conditional logistic-regression model in which the dependent variable was the hospitalization of a spouse. The predictor variables were the death of a partner, the number of days since observation began, and the number of days squared. The death of a partner itself could not be used as the dependent variable because 
it is a monotonic function of time, leading to quasi-complete separation; nevertheless, the exponentiated coefficient for the death of a partner could be interpreted as the odds ratio for the effect of spousal hospitalization on the death of a partner. ${ }^{21}$

Because each couple was a separate stratum, only within-couple variation was used to estimate the effects; therefore, each couple served as its own control. The hospitalization variable was designated as an indicator of whether a spouse was hospitalized (overall or with a particular diagnosis) within the previous $30,60,90,180,360$, or 720 days. As implemented, these models estimated the effect of the hospitalization of a spouse, with or without subsequent death, on the mortality of the partner.

$\mathrm{P}$ values for all analyses are two-sided. We computed the confidence intervals for the relative size of the coefficients describing the effect of spousal hospitalization as compared with spousal death with use of the delta method.

RESULTS

\section{ATTRIBUTES OF THE COHORT}

The mean ages of patients at the start of the study were 75.4 years for men and 72.9 years for women. In 79.1 percent of couples, the man was older; 90.1 percent of men and 92.1 percent of women were white; 5.4 percent of the couples were living in poverty. The mean baseline Charlson score was 0.50 for men and 0.30 for women. From January 1, 1993, to January 1, 2002, 383,480 ( 74 percent) of the men and 347,269 (67 percent) of the women were hospitalized at least once. During this period, 252,557 men (49 percent) and 156,004 women (30 percent) died; in 95,330 couples (18 percent), both the husband and wife died.

\section{MORTALITY AFTER THE HOSPITALIZATION OF A SPOUSE}

Table 1 shows the percentage of persons who died within one year after the hospitalization of a spouse, overall and according to disease category; the numbers are unadjusted for any individual attributes and are listed roughly in order from least effect to greatest effect. For example, whereas 6.4 percent of men died within a year after a spouse's hospitalization for colon cancer, 6.9 percent died within a year after a spouse's hospitalization for stroke, 7.5 percent after a spouse's hospitalization for psychiatric disease, and 8.6 percent after a spouse's hospitalization for dementia. Whereas 3.0 percent of women died within a year after a spouse's hospitalization for colon cancer, 3.7 percent died within a year after a spouse's hospitalization for stroke, 5.7 percent after a spouse's hospitalization for psychiatric disease, and 5.0 percent after a spouse's hospitalization for dementia. As a benchmark, at baseline, 5.6 percent of men whose wives had not previously been hospitalized died within a year, and 2.6 percent of women whose husbands had not been hospitalized died within a year.

Table 1 also reports the percentage of spouses who died within a year after their own hospitalization; as expected, the diseases show substantial variation in lethality, with one-year death rates varying from 7.3 percent (for women with psychiatric disease) to 82.0 percent (for men with pancreatic cancer). This observation supports the importance of separating the possible effect of spousal illness from that of spousal death on the mortality of a partner.

\section{ADJUSTED ANALYSES}

Table 2 provides estimates of the association between spousal hospitalization and the risk of death of the partner after accounting for whether the spouse died and after adjusting for other measured attributes of both parties, including age and baseline morbidity, by Cox regression analysis. For example, the hospitalization of a woman for colon cancer is not significantly associated with the subsequent risk of death of her husband (hazard ratio, 1.02; 95 percent confidence interval, 0.95 to 1.09), whereas the hospitalization of a woman for stroke raises her husband's risk of death by 6 percent (hazard ratio, 1.06; 95 percent confidence interval, 1.03 to 1.09), hospitalization for congestive heart failure by 12 percent (hazard ratio, 1.12; 95 percent confidence interval, 1.07 to 1.16), for hip fracture or other serious fracture by 15 percent (hazard ratio, 1.15; 95 percent confidence interval, 1.11 to 1.18), for psychiatric disease by 19 percent (hazard ratio, 1.19; 95 percent confidence interval, 1.12 to 1.26), and for dementia by 22 percent (hazard ratio, 1.22; 95 percent confidence interval, 1.12 to 1.32).

In a similar manner, the hospitalization of a man for colon cancer has no significant effect on the risk of death of his wife (hazard ratio, 1.01; 95 percent confidence interval, 0.93 to 1.10 ), 


\begin{tabular}{|c|c|c|}
\hline \multirow[t]{2}{*}{ Diagnosis of Wife } & $\begin{array}{l}\text { Wives Hospitalized with Disease } \\
\text { and Mortality at } 1 \text { Year }\end{array}$ & $\begin{array}{l}\text { Mortality among Husbands within } \\
1 \text { Year after Hospitalization of Wife }\end{array}$ \\
\hline & no. (mortality [\%]) & $\%$ \\
\hline \multicolumn{3}{|l|}{ Cancer } \\
\hline Lung & $2,416(55.1)$ & 5.6 \\
\hline Colon & $5,056(19.4)$ & 6.4 \\
\hline Pancreas & $641(81.0)$ & 6.9 \\
\hline Leukemia or lymphoma & $1,538(52.9)$ & 7.5 \\
\hline All other forms & $18,158(27.6)$ & 5.1 \\
\hline Abdominal surgical disease & $27,042(8.0)$ & 6.3 \\
\hline Pneumonia & $15,884(17.9)$ & 7.2 \\
\hline Sepsis & $3,971(27.7)$ & 7.4 \\
\hline Ischemic heart disease & $30,188(13.4)$ & 6.2 \\
\hline Stroke & $24,674(18.6)$ & 6.9 \\
\hline Congestive heart failure & $13,261(25.6)$ & 7.5 \\
\hline Chronic obstructive pulmonary disease & $8,335(13.9)$ & 6.4 \\
\hline Fracture of hip or other serious fracture & $18,087(12.6)$ & 8.6 \\
\hline Psychiatric disease & $4,893(7.3)$ & 7.5 \\
\hline Dementia & $2,642(21.2)$ & 8.6 \\
\hline All other diagnoses & $170,483(9.8)$ & 5.9 \\
\hline Any diagnosis (total) & $347,269(13.8)$ & 6.3 \\
\hline \multirow[t]{2}{*}{ Diagnosis of Husband } & $\begin{array}{l}\text { Husbands Hospitalized with Disease } \\
\text { and Mortality at } 1 \text { Year }\end{array}$ & $\begin{array}{c}\text { Mortality among Wives within } \\
1 \text { Year after Hospitalization } \\
\text { of Husband }\end{array}$ \\
\hline & no. (mortality [\%]) & $\%$ \\
\hline \multicolumn{3}{|l|}{ Cancer } \\
\hline Lung & $4,329(66.2)$ & 3.4 \\
\hline Colon & $6,559(23.7)$ & 3.0 \\
\hline Pancreas & $678(82.0)$ & 3.5 \\
\hline Leukemia or lymphoma & $2,121(65.1)$ & 3.4 \\
\hline All other forms & $21,263(36.7)$ & 2.8 \\
\hline Abdominal surgical disease & $26,623(12.8)$ & 3.5 \\
\hline Pneumonia & $23,594(30.2)$ & 4.5 \\
\hline Sepsis & $5,022(34.9)$ & 4.0 \\
\hline Ischemic heart disease & $50,596(15.9)$ & 2.9 \\
\hline Stroke & $31,471(22.7)$ & 3.7 \\
\hline Congestive heart failure & $18,644(34.5)$ & 4.3 \\
\hline Chronic obstructive pulmonary disease & $9,532(24.1)$ & 4.1 \\
\hline Fracture of hip or other serious fracture & $9,800(28.1)$ & 5.1 \\
\hline Psychiatric disease & $2,666(19.5)$ & 5.7 \\
\hline Dementia & $3,348(37.8)$ & 5.0 \\
\hline All other diagnoses & $167,234(17.2)$ & 3.4 \\
\hline Any diagnosis (total) & $383,480(21.8)$ & 3.5 \\
\hline
\end{tabular}




\begin{tabular}{|c|c|c|}
\hline \multirow[t]{2}{*}{ Variable } & \multicolumn{2}{|c|}{$\begin{array}{l}\text { Hazard Ratio for Death } \\
(95 \% \mathrm{Cl})\end{array}$} \\
\hline & Male Partner & Female Partner \\
\hline \multicolumn{3}{|l|}{ Spousal diagnosis on hospitalization } \\
\hline \multicolumn{3}{|l|}{ Cancer } \\
\hline Lung & $0.94(0.80-1.10)$ & $1.14(0.96-1.34)$ \\
\hline Colon & $1.02(0.95-1.09)$ & $1.01(0.93-1.10)$ \\
\hline Pancreas & $0.86(0.54-1.39)$ & $1.18(0.65-2.13)$ \\
\hline Leukemia or lymphoma & $1.08(0.91-1.27)$ & $1.08(0.87-1.34)$ \\
\hline All other forms & $0.99(0.95-1.03)$ & $0.96(0.91-1.01)$ \\
\hline Abdominal surgical disease & $1.04(1.01-1.06) \dagger$ & $1.03(0.99-1.06)$ \\
\hline Pneumonia & $1.06(1.02-1.10) \dagger$ & $1.06(1.02-1.10) \dagger$ \\
\hline Sepsis & $1.09(1.01-1.17) \doteqdot$ & $1.07(0.98-1.17)$ \\
\hline Ischemic heart disease & $1.05(1.02-1.07) \dagger$ & $0.97(0.94-0.99) \div$ \\
\hline Stroke & $1.06(1.03-1.09) \dagger$ & $1.05(1.01-1.09) \div$ \\
\hline Congestive heart failure & $1.12(1.07-1.16) \dagger$ & $1.15(1.09-1.20) \dagger$ \\
\hline Chronic obstructive pulmonary disease & $1.12(1.07-1.18) \dagger$ & $1.13(1.06-1.21) \dagger$ \\
\hline Fracture of hip or other serious fracture & $1.15(1.11-1.18) \dagger$ & $1.11(1.04-1.17) \dagger$ \\
\hline Psychiatric disease & $1.19(1.12-1.26) \dagger$ & $1.32(1.18-1.46) \dagger$ \\
\hline Dementia & $1.22(1.12-1.32) \dagger$ & $1.28(1.14-1.43) \dagger$ \\
\hline All other diagnoses & $1.02(1.01-1.03) \dagger$ & $1.01(0.99-1.03)$ \\
\hline Spousal death & $1.21(1.19-1.22) \dagger$ & 1.17 (1.15-1.19) \\
\hline
\end{tabular}

whereas hospitalization of a man for stroke raises his wife's risk of death by 5 percent (hazard ratio, 1.05; 95 percent confidence interval, 1.01 to 1.09 ), hospitalization for congestive heart failure by 15 percent (hazard ratio, 1.15; 95 percent confidence interval, 1.09 to 1.20), for hip fracture or other serious fracture by 11 percent (hazard ratio, 1.11; 95 percent confidence interval, 1.04 to 1.17), for psychiatric disease by 32 percent (hazard ratio, 1.32; 95 percent confidence interval, 1.18 to 1.46 ), and for dementia by 28 percent (hazard ratio, 1.28; 95 percent confidence interval, 1.14 to 1.43 ).

The results in Table 2 also show that the death of a spouse itself is associated with an increase in the risk of death of 21 percent for men and 17 percent for women. This estimate of the bereavement effect compares the effect of the death of a spouse with the effect of having a spouse who is both alive and well.

To assess the relative effect of spousal hospitalization and death, we constructed a simplified
Cox model (not shown) that included a single indicator for a hospitalization (instead of the 16 diagnosis indicators), the spousal-death variable, and the same adjustment covariates that were included in our primary model. We found that the hospitalization of a woman was associated with an increase in her husband's risk of death of 4.5 percent (hazard ratio, 1.05; 95 percent confidence interval, 1.04 to 1.06), and the hospitalization of a man was associated with an increase in his wife's risk of death of 2.7 percent (hazard ratio, 1.03; 95 percent confidence interval, 1.01 to 1.04). The death of a wife was associated with an increase in a husband's risk of death of 21 percent (hazard ratio, 1.21; 95 percent confidence interval, 1.19 to 1.22), and the death of a husband was associated with an increase in a wife's risk of death of 17 percent (hazard ratio, 1.17; 95 percent confidence interval, 1.15 to 1.19). Hence, during the entire follow-up period, a comparison of the overall effect of spousal hospitalization with that of spousal death revealed that for men the 


\begin{tabular}{|c|c|c|}
\hline \multicolumn{3}{|l|}{ Table 2. (Continued.) } \\
\hline \multirow[t]{2}{*}{ Variable } & \multicolumn{2}{|c|}{$\begin{array}{l}\text { Hazard Ratio for Death } \\
\text { (95\% CI) }\end{array}$} \\
\hline & Male Partner & Female Partner \\
\hline \multicolumn{3}{|l|}{ Characteristics of couples } \\
\hline \multicolumn{3}{|l|}{ Age - per yr } \\
\hline Husband & 1.09 (1.09-1.09) & $1.00(1.00-1.00) \mathbb{\int}$ \\
\hline Wife & $1.00(1.00-1.00) \mathbb{8}$ & $1.10(1.09-1.10) \dagger$ \\
\hline Wife older than husband & $1.05(1.04-1.06) \dagger$ & $1.04(1.03-1.06) \dagger$ \\
\hline Couple below poverty line & $1.34(1.32-1.36) \dagger$ & $1.43(1.40-1.46) \dagger$ \\
\hline \multicolumn{3}{|l|}{ Charlson scoreq } \\
\hline \multicolumn{3}{|l|}{ Husband } \\
\hline 1 & $1.52(1.50-1.54) \dagger$ & $0.98(0.96-0.99) \div$ \\
\hline$\geq 2$ & $2.21(2.18-2.23) \dagger$ & $0.97(0.96-0.99) \dagger$ \\
\hline \multicolumn{3}{|l|}{ Wife } \\
\hline 1 & $1.01(0.99-1.03)$ & $1.97(1.90-1.97) \dagger$ \\
\hline$\geq 2$ & $0.99(0.98-1.01)$ & $2.96(2.92-3.00) \dagger$ \\
\hline \multicolumn{3}{|c|}{ Total weeks of hospitalization (1990-1992) - per wk } \\
\hline Husband & $1.03(1.03-1.03) \dagger \delta$ & $0.99(0.99-0.99) \dagger$ \\
\hline Wife & $0.99(0.99-0.99) \dagger$ & $1.03(1.03-1.03) \div \int$ \\
\hline \multicolumn{3}{|l|}{ Black race $\|$} \\
\hline Husband & $1.10(1.03-1.17) \dagger$ & $1.12(1.03-1.22) \dagger$ \\
\hline Wife & $0.95(0.89-1.02)$ & $0.96(0.88-1.04)$ \\
\hline
\end{tabular}

* Cl denotes confidence interval. The table shows Cox regression models of survival, separately for husbands and wives, with hazard ratios and 95 percent confidence intervals. Subjects were followed for nine years, from January 1, 1993, to January 1, 2002. The death of a spouse and spousal hospitalization were treated as time-varying covariates during follow-up. Spousal diagnoses were defined as the principal diagnosis noted during the first hospitalization, if any, during follow-up. All other covariates were measured at baseline on January 1, 1993. Model estimation has been restricted to the 392,530 couples in which both partners were at least 68 years old.

$\dagger P<0.01$.

$\leftarrow P<0.05$.

$\int$ The confidence interval has been rounded to two decimal places.

I The Charlson score measures the number of coexisting conditions, weighted according to their relative effects on mortality, with the higher numbers indicating a greater burden of illness. The omitted category for measures on the Charlson score is zero.

$\|$ Race was determined according to Medicare records. The omitted category for race is white; coefficients for other categories of race or ethnic group - including Asian, Hispanic, other, and unknown — are not shown here.

risk of death associated with spousal hospitalization was 22 percent of the risk associated with spousal death (95 percent confidence interval, 17 to 27 percent); for women, the risk of death associated with spousal hospitalization was 16 percent of the risk associated with spousal death (95 percent confidence interval, 8 to 24 percent).

We also used this simplified model (not shown) to evaluate how age, race, and poverty status modified the effect of spousal hospitalization. For women, the effect of a husband's hospitalization increased with age and poverty. For men, the effect of a wife's hospitalization increased only with age. There were only small differences by race in the effect of hospitalization.

Finally, additional analyses that assessed the effect of spousal hospitalization or death on the mortality of the partner within 30 days after the hospitalization or death showed that the effect of spousal hospitalization was relatively more pronounced during this short period, with hazard ratios for spousal hospitalization that were almost as large as those associated with spousal death. The hospitalization of a wife within the previous 30 days was associated with an increase in a husband's risk of death of 35 percent during 
this period (hazard ratio, 1.35; 95 percent confidence interval, 1.29 to 1.41 ), and the hospitalization of a husband increased a wife's risk of death by 44 percent (hazard ratio, 1.44; 95 percent confidence interval, 1.35 to 1.52). The death of a wife within the previous 30 days was associated with an increase in a husband's risk of death of 53 percent (hazard ratio, 1.53; 95 percent confidence interval, 1.44 to 1.63), and the death of a husband was associated with an increase in a wife's risk of death of 61 percent (hazard ratio, 1.61; 95 percent confidence interval, 1.51 to 1.70). Hence, a comparison of the effect on partners of spousal hospitalization with that of spousal death in the previous 30 days revealed that for men the effect of spousal hospitalization was 65 percent as large as the effect of spousal death (95 percent confidence interval, 49 to 81 percent). For women, the effect of spousal hospitalization was 72 percent as large as the effect of spousal death (95 percent confidence interval, 54 to 89 percent).

Figure 1A and Figure 2A show the effect of spousal hospitalization for any diagnosis on the risk of death, with use of the case-time-control method and an analysis of a two-year time period after spousal hospitalization. When a spouse was hospitalized, the partner's risk of death increased significantly above baseline and remained elevated for up to two years. These patterns were apparent even after controlling for all stable measured or unmeasured attributes of the couples and without regard to whether the hospitalized spouse lived or died. Figures $1 \mathrm{~B}$ through $1 \mathrm{~F}$ and Figures $2 \mathrm{~B}$ through 2F show the effect of the hospitalization, depending on the diagnosis in the spouse, on the risk of death during a two-year period for a merely illustrative selection of five conditions. The graphs are all U-shaped, typically with a nadir at 90 to 180 days. Numerical data about all 16 conditions appear in the Supplementary Appendix, which is available with the full text of this article at www. nejm.org.

\section{DISCUSSION}

People may have health consequences as a result of the illness of a spouse, the death of a spouse, or both. We found that serious spousal illness (as marked by hospitalization) and spousal death appear to be independently associated with the risk of death of the partner, for both men and women. Indeed, within the first 30 days, the hos- pitalization of a spouse was associated with a risk of death for the partner that was almost as great as that associated with the death of a spouse. Over the long run, for men, hospitalization of a spouse was associated with a risk of death that was 22 percent of the risk associated with the death of a spouse; for women, the risk was 16 percent of the risk associated with spousal death.

Moreover, certain illnesses in spouses were even more harmful to partners than these overall associations suggest. We hypothesized that the effect of the illness the spouse had could vary - in other words, the more a disease interfered with physical or mental ability (regardless of the lethality of the disease), the worse the outcome for the partner. Thus, our interest in the heterogeneity of diseases was driven by our interest in possible mechanisms underlying the association between spousal hospitalization and partner mortality. Moreover, an association between more burdensome diseases (whatever their intrinsic lethality) and a greater risk of death in partners would represent a kind of dose-response evidence.

Previous work has indeed documented that diseases vary in their effect on the activities of daily living (ADL) of afflicted persons..22,23 One study showed that stroke, hip fracture, dementia, and congestive heart failure compromised ADL but that myocardial infarction, chronic obstructive pulmonary disease, and cancer had less of an effect. ${ }^{24}$ Another study showed that stroke and hip fracture were more disabling than either congestive heart failure or cancer. ${ }^{22}$ And a metaanalysis of data from 15,000 reports about patients ranked disease groups as follows, from greatest to least consequence on physical and mental functioning: cerebrovascular conditions, cardiovascular conditions, respiratory conditions, and oncologic conditions. ${ }^{25}$

Our results indicate that hospitalization for various diseases may indeed differentially affect partners. Cancer diagnoses appear not to be so burdensome, in the sense of increasing a partner's risk of death. And although dementia has a great effect on partners, other physical and mental illnesses, such as chronic obstructive pulmonary disease and psychiatric conditions, appear to rival it, even if they are less lethal. Finally, the findings that the consequences of spousal illness are roughly equal for men and women and also that the diseases have similar rankings in men and women lend support to the supposition that certain dis- 


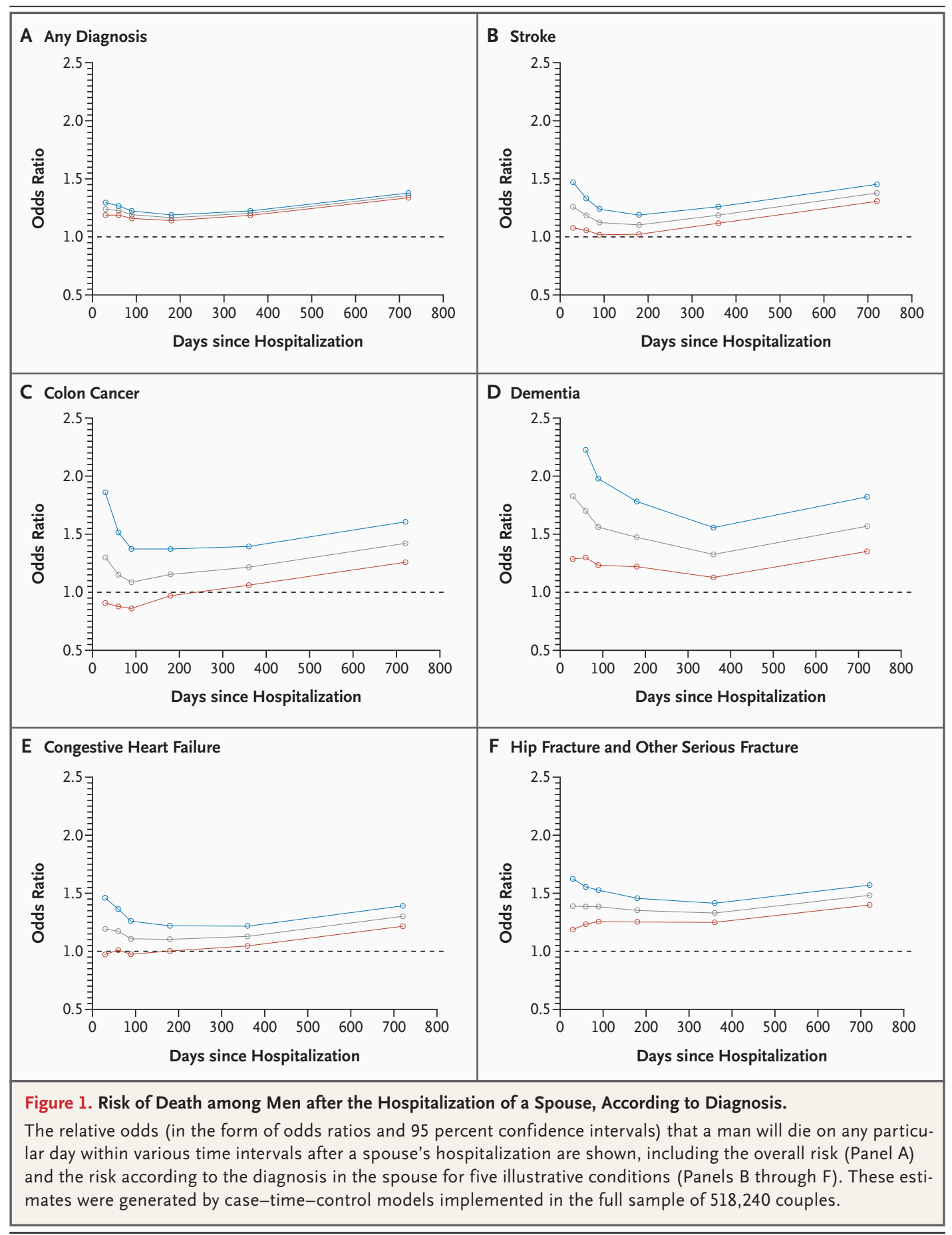

eases may have an intrinsically burdensome quality that may underlie the observed associations.

Two possible mechanisms for these associations are that spousal illness or death may impose stress on a partner and that spousal illness or death may deprive a partner of social, emotional, economic, or other practical support. ${ }^{26,27}$ When a spouse falls seriously ill (or dies), partners may show an increase in harmful behavior, ranging from drinking to bad dietary practices to accidentprone activities, with an attendant rise in the hazard of death. ${ }^{28}$ Stress and a lack of social support 


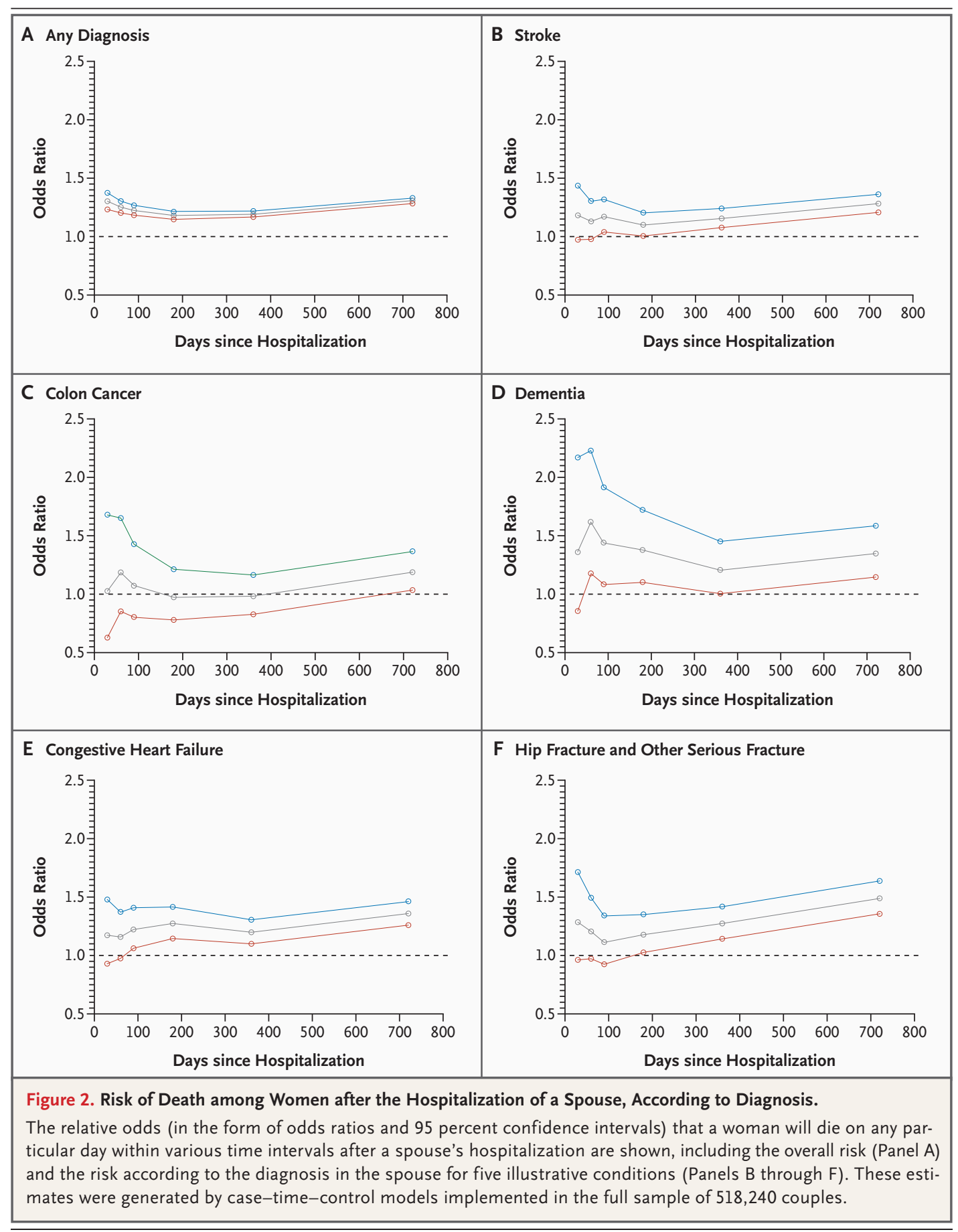

may also adversely affect immunologic measures. ${ }^{29}$ Spousal hospitalization may be especially stressful to those who are already vulnerable. We found that older partners are more likely to die in response to the hospitalization of a spouse and that, at least for women, the hospitalization of a spouse is more harmful if the couple is poor.
However, although illness and death of a spouse create stress and compromise social support, these effects may occur over various time frames. For example, the stress effect may last for a few weeks or months, and the support effect may last for several years. Moreover, the stress effect may have immediate onset and decrease 
with time, and the support effect may increase with time. Therefore, we supposed that the effect of having a sick spouse might vary according to the duration of the illness in hard-to-predict ways. We found, overall and across a range of diagnoses, a U-shaped pattern, with a nadir at 90 to 180 days. One possible interpretation of this finding is that early in the course of a spouse's illness, stress affects the partner in ways to which he or she eventually adapts, so that the health risks of being a caregiver decline. Eventually, however, the lack of social support that is associated with the illness (or death) of a spouse becomes a problem, and health risks increase again. A previous study that looked at the risk of death in partners according to the duration of bereavement (i.e., the time since the death of a spouse) suggests a similar U-shaped pattern. ${ }^{30}$

Observational studies are always vulnerable to confounding factors. For example, if one spouse falls ill or dies, the partner may also fall ill or die, but not because the partner is affected by the spouse's illness. Rather, the partner may fall ill because the two spouses share traits that determine the health outcomes of both. This possibility has often been overlooked in studies of caregiver burden or bereavement. However, the implementation of statistical controls for relevant variables in the Cox models or, more important, the use of the case-time-control method (which accounts for any stable attributes of couples, even if they are unmeasured) helps to mitigate this concern. Unmeasurable unstable attributes of couples, however, could be persistent confounders of the association we observed. We were also constrained by the fact that we did not know whether the partner provided any care or actually experienced stress; the very large data set that was required for our study of effects on mortality necessarily lacked such detail.
Interpersonal health effects have clinical and policy significance. Most generally, it is clear that a person's illness or death can have health consequences for others in his or her social network. ${ }^{31-34}$ This observation, in turn, means that efforts to reduce disease, disability, and death can be self-reinforcing, since a decrease in the burden of these events in one person can have cascading benefits for others. Health care might indeed be more socially efficient, and more cost-effective, than is suggested by looking at individual cases alone. Policymakers with a collective perspective, such as governmental or insurance entities, might care about such effects.

Our findings can also inform the delivery of support services. The training and assistance of spouses who serve as caregivers can lower costs and also improve the health of patients and partners alike. ${ }^{35}$ Our work suggests that such interventions might even decrease mortality among partners. Our work also suggests that such interventions are especially likely to be useful in certain diseases, such as stroke and dementia. Moreover, the timing of such interventions might optimally be matched to the riskiest times for partners - for example, just after hospitalization of the spouse. Finally, since seriously ill patients themselves care about the health of their loved ones, ${ }^{36}$ they have a substantial interest in mitigating any effects of their own illness on others.

Supported by a grant (R-01 AG17548-01) from the National Institutes of Health (NIH).

No potential conflict of interest relevant to this article was reported.

We are indebted to Laurie Meneades for data-programming assistance in building the analytic data set; to Felix Elwert for statistical programming and for comments on the manuscript; and to the participants in the National Bureau of Economic Research Workshop on Aging and Disability for providing helpful feedback (supported by NIH grant P-30 AG12810 and by the Mary Woodard Lasker Charitable Trust and the Michael E. DeBakey Foundation).

REFERENCES

1. Lillard LA, Waite LJ. 'Til death do us part: marital disruption and mortality. Am J Sociol 1995;100:1131-56.

2. Martikainen P, Valkonen T. Mortality after the death of a spouse: rates and causes of death in a large Finnish cohort. Am J Public Health 1996;86:1087-93.

3. Dunkin JJ, Anderson-Hanley C. Dementia caregiver burden: a review of the literature and guidelines for assessment and intervention. Neurology 1998;51: Suppl:S53-S60.
4. Shaw WS, Patterson TL, Semple SJ, et al. Longitudinal analysis of multiple indicators of health decline among spousal caregivers. Ann Behav Med 1997;19:1019.

5. Schulz R, Beach SR. Caregiving as a risk factor for mortality: the Caregiver Health Effects Study. JAMA 1999;282:2215-9.

6. Clipp EC, George LK. Dementia and cancer: a comparison of spouse caregivers. Gerontologist 1993;33:534-41.

7. Pruchno RA, Resch NL. Abberrant be- haviors and Alzheimer's disease: mental health effects on spouse caregivers. J Gerontol 1989;44:S177-S182.

8. Scholte op Reimer WJ, de Haan RJ, Rijnders PT, Limburg M, van den Bos GA. The burden of caregiving in partners of long-term stroke survivors. Stroke 1998; 29:1605-11

9. Magliano L, Fiorillo A, DeRosa C, Malangone C, Maj M, National Mental Health Project Working Group. Family burden in long-term diseases: a comparative 
study in schizophrenia vs. physical disorders. Soc Sci Med 2005;61:313-22.

10. Hatten J. Medicare's common denominator: the covered population. Health Care Financ Rev 1980;2:53-64.

11. Iwashyna TJ, Zhang JX, Lauderdale DS, Christakis NA. A methodology for identifying married couples in Medicare data mortality, morbidity, and health care use among the married elderly. Demography 1998;35:413-9.

12. Iwashyna TJ, Brennan G, Zhang JX, Christakis NA. Finding married couples in Medicare claims data. Health Services Outcomes Res Methodol 2002;3:75-86.

13. Hall MJ, DeFrances CJ. 2001 Nationa Hospital Discharge Survey. Advance data from Vital and Health Statistics, No. 332. Hyattsville, Md.: National Center for Health Statistics, 2003.

14. Zhang J, Iwashyna TJ, Christakis NA. The performance of different lookback periods and sources of information for Charlson comorbidity adjustment in Medicare claims. Med Care 1999;37:1128-39.

15. Cooper GS, Yuan Z, Stange KC, Dennis LK, Amini SB, Rimm AA. The sensitivity of Medicare claims data for case ascertainment of six common cancers. Med Care 1999;37:436-44.

16. Benesch C, Witter DM Jr, Wilder AL, Duncan PW, Samsa GP, Matchar DB. Inaccuracy of the International Classification of Diseases (ICD-9-CM) in identifying the diagnosis of ischemic cerebrovascular disease. Neurology 1997;49:660-4. [Erratum, Neurology 1998;50:306.]

17. Lauderdale DS, Goldberg J. The expanded racial and ethnic codes in the Medi- care data files: their completeness of coverage and accuracy. Am J Public Health 1996;86:712-6.

18. Pope GC, Adamache KW, Walsh EG, Khandker RK. Evaluating alternative risk adjusters for Medicare. Health Care Financ Rev 1998;20:109-29.

19. Suissa S. The case-time-control design: further assumptions and conditions. Epidemiology 1998;9:441-5.

20. Greenland S. Confounding and exposure trends in case-crossover and casetime-control designs. Epidemiology 1996; 231-9.

21. Allison PD, Christakis NA. Fixed effects methods for the analysis of nonrepeated events. Sociol Methodol (in press). 22. Ferrucci L, Guralnik JM, Pahor M Corti MC, Havlik RJ. Hospital diagnoses, Medicare charges, and nursing home admissions in the year when older persons become severely disabled. JAMA 1997;277: 728-34.

23. Rosen $\mathrm{A}, \mathrm{Wu}$ J, Chang BH, Berlowitz D, Ash A, Moskowitz M. Does diagnostic information contribute to predicting functional decline in long-term care? Med Care 2000;38:647-59.

24. Gill TM, Allore HG, Holford TR, Guo Z. Hospitalization, restricted activity, and the development of disability among older persons. JAMA 2004;292:2115-24 25. Sprangers MA, de Regt EB, Andries F, et al. Which chronic conditions are associated with better or poorer quality of life? J Clin Epidemiol 2000;53:895-907.

26. House JS, Landis KR, Umberson D. Social relationships and health. Science 1988;241:540-5.
27. Thoits PA. Stress, coping, and social support processes: where are we? What next? J Health Social Behav 1995; Special No.:53-79.

28. Umberson D. Gender, marital status and the social control of health behavior. Soc Sci Med 1992;34:907-17.

29. Cohen S, Doyle WJ, Skoner DP, Rabin BS, Gwaltney JM Jr. Social ties and susceptibility to the common cold. JAMA 1997; 277:1940-4.

30. Martikainen P, Valkonen T. Mortality after death of spouse in relation to duration of bereavement in Finland. J Epidemiol Community Health 1996;50:264-8.

31. Christakis NA. Social networks and collateral health effects. BMJ 2004;329: 184-5.

32. Christakis NA, Iwashyna TJ. The health impact of health care on families: a matched cohort study of hospice use by decedents and mortality outcomes in surviving, widowed spouses. Soc Sci Med 2003;57:46575.

33. Li J, Laursen TM, Precht DH, Olsen J, Mortensen PB. Hospitalization for mental illness among parents after the death of a child. N Engl J Med 2005;352:1190-6.

34. Elwert F, Christakis NA. Widowhood and race. Am Sociol Rev (in press).

35. Kalra L, Evans A, Perez I, et al. Training carers of stroke patients: randomised controlled trial. BMJ 2004:328:1099-101.

36. Steinhauser KE, Christakis NA, Clipp EC, McNeilly M, McIntyre L, Tulsky JA. Factors considered important at the end of life by patients, family, physicians, and other care providers. JAMA 2000;284:2476-82. Copyright $\odot 2006$ Massachusetts Medical Society.

VIEW CURRENT JOB POSTINGS AT THE NEJM CAREERCENTER Visit our online CareerCenter for physicians at www.nejmjobs.org to see the expanded features and services available. Physicians can conduct a quick search of the public data base by specialty and view hundreds of current openings that are updated daily online at the CareerCenter. 